\title{
Knowledge, Attitude and Practice of Community Pharmacists towards Adverse Drug Reactions Reporting
}

\author{
Easwaran Vigneshwaran 1,2,*, Veluru Harichandana' ${ }^{1}$, Mantargi Mohammed Jaffar Sadiq ${ }^{1,3}$, Sirajudeen Shaik Alavudeen², Noohu Abdulla \\ Khan $^{2}$, Tajmulla Ahmed ${ }^{4}$ \\ 'Department of Pharmacy Practice, Raghavendra Institute of Pharmaceutical Education and Research (RIPER), Anantapuramu, Andhra Pradesh, INDIA. \\ Department of Clinical Pharmacy, College of Pharmacy, King Khalid University, Abha, KINGDOM OF SAUDI ARABIA. \\ ${ }^{3}$ Department of Pharmacology, Batterjee Medical College, North - Obhur, Jeddah, KINGDOM OF SAUDI ARABIA. \\ ${ }^{4}$ Associate Professor of Dentistry, Department of Prosthodontics, Batterjee Medical College, North - Obhur, Jeddah, KINGDOM OF SAUDI ARABIA.
}

\begin{abstract}
Background: Spontaneous reporting systems (SRSs) play an important role in identifying adverse drug reactions. In most of the developed countries, community pharmacists contribute to the pharmacovigilance system to a greater deal. Objectives: Present investigation is designed to evaluate the impact of clinical pharmacists' educational intervention on ADRs and pharmacovigilance program of India (PvPI) among community pharmacists in Anantapur district, Andhra Pradesh, India. Methods: It was a single group, pre - post interventional trial. A 'KAP' questionnaire regarding ADRs in accordance with the PVPI was prepared and validated by experts. The initial phase of survey was conducted by approaching the community pharmacists at their premises. A total of 58 practicing community pharmacists in Anantapur district of south India were included in the study. All the participated community pharmacists were invited for an education session with an aim to improve ADR reporting and to make aware of PVPI. Results: After the educational intervention, a significant improvement in knowledge, attitude and practice towards ADRs identification and reporting and $\mathrm{PVPI}$ among the study participants was evident. In addition, age
\end{abstract}

and educational level were impactful on KAP of community pharmacists for the same. Conclusion: Based on the results of this study, it is necessary to offer continuous educational programs and hands-on training for spontaneous reporting of ADRs until we reach the point that voluntary reporting of ADRs becomes accessible and habitual among the community pharmacists.

Key words: Community Pharmacists, ADR reporting, KAP, Pharmacovigilance, ADE, Continuous Pharmacy Education.

Correspondence

Dr. Easwaran Vigneshwaran

Department of Clinical Pharmacy, College of Pharmacy, King Khalid University, Abha, KINGDOM OF SAUDI ARABIA

Phone: $+91-9790352665$

Email:vickku_e@yahoo.com.sg

DOI: $10.5530 / j y p .2020 .12 .15$

\section{INTRODUCTION}

The drug safety monitoring programs around the world profoundly depend on spontaneous reporting of adverse drug reactions (ADRs) from healthcare professionals. Spontaneous reporting systems (SRSs) play an important role in identifying $\mathrm{ADRs}^{1}$ which is considered to be a major cause of increased morbidity and mortality along with huge economic burden. ${ }^{2,3}$ Plenty of factors are associated with under-reporting of ADRs and the major one is lack of knowledge and attitude. ${ }^{4}$ Continuous education programs for healthcare professionals on pharmacovigilance, increased accessibility of yellow cards, pharmacists' ward round participation and active training to health care professionals were proposed by various research studies to improve the knowledge and attitude towards ADR identification and reporting. ${ }^{3,5,6}$

Previous studies has revealed that pharmacists can be handy reporting ADRs timely. Preferably in community pharmacy setup because of their comprehensive knowledge of drugs and the closeness to the ADRs effect on patients every day. ${ }^{7,8}$ In most developed countries, health care professionals including community pharmacists contribute to the pharmacovigilance system to a bigger extent and also a part of formal reporting system. ${ }^{9}$ In India, all the health care professionals are encouraged to report the ADRs. Various regional centers for receiving the reports were setup ${ }^{10}$ under the supervision of the 'Indian Pharmacopoeia Commission' (IPC) aligned under the ministry of health and family welfare (MoHFW) has been functioning as the National Co-ordination Centre
(NCC) for PvPI since April 2011 with this there has been rapid progress in reporting of ADRs by the healthcare professionals in recent years is appreciable. ${ }^{11}$

Several studies have been conducted in different countries to examine pharmacists' knowledge and attitudes towards ADR reporting and have identified the crucial factors affecting their knowledge and attitude with an aim to improve the quality of reporting ADRs. In India ADR reporting by the community pharmacists is compromised due to poor knowledge and practice ${ }^{6}$ which shall be resolved by adequate motivation through regular pharmacy educational programs. Therefore, the present study was undertaken to find out the impact of educational intervention towards ADR reporting and PvPI among registered community pharmacists those who were practicing in resource-limited settings of south India.

\section{METHODOLOGY}

\section{Study design and sampling}

It was a single group, pre - post interventional trial. The non-probabilistic convenient sampling technique was used to recruit the study participants. The research team extended invitation to all the registered community pharmacists, who are practicing in and around Anantapur district, Andhra Pradesh, South India. Interested, qualified and regis- 
tered participants, who were willing to provide consent, were included in the study.

\section{Study tool}

The outcome was measured using a suitable self-administered questionnaire designed by referring similar kinds of literatures with input from the experts. ${ }^{4,13}$ An initial draft of the questionnaire was subjected to content validity and face validity. The draft questionnaire was sent to a group of experts (health care professionals) for review. Their suggestions were obtained and the second version of the questionnaire was designed, which was then sent to five community pharmacists to ascertain the questionnaire was simple and brief. The finalized questionnaire was a dichotomous type comprised of 18 items with three domains i.e. knowledge ( 4 items), attitude ( 8 items) and practice ( 6 items) which are essential for the fruitful completion of the present study.

\section{Outcome measures}

The levels of knowledge, attitude and practice towards ADR reporting system and PvPI were considered as major outcome measures. The frequencies of correct responses were taken for required analysis.

Intervention and data collection: The recruited community pharmacist's were analyzed for the improvements in KAP towards ADR reporting and PvPI after the educational intervention. During the first phase of the study, the research team conducted a structured questionnaire-based interview about the ADR reporting system and PvPI with the community pharmacists at their premises and recorded the responses. During the second phase of the study, the previously interviewed community pharmacists were invited to attend an interventional educational program at the pharmacy academic institution. The full-day educational intervention included lectures and group discussions. During the interventional program, the participants were educated on filling ADR reporting form, list of ADR reporting centers, the process of ADR reporting and the role of PvPI. Further, the community pharmacists received regular short message service (SMS) to their mobiles on an alternative day's basis regarding the ADR reporting system and PvPI sent by the research team. During the third phase of the study, i.e. after three months of intervention another interview with the participants was conducted with the same questionnaire.

Data analysis: The data was transcribed into Microsoft Excel and exported to statistical package for social sciences (SPSS) for windows, version 21 for statistical analysis. Descriptive statistics were used to illustrate the demographic characteristics of the study participants. Differences in the frequency of correct KAP responses before and after the intervention, the association between the demographic characteristics and the post interventional responses were performed using the chi-square test. ${ }^{14,15}$ The $p$ value less than or equal to 0.05 was considered statistical significant.

\section{RESULTS}

\section{Demographic characteristics}

Out of 65 pharmacists included in the study, only 58 participants responded positively and the rest were considered as follow up failures. The mean age of the study participants was identified to be 43.1 years with an average experience of 19.7 years. The number of study participants was higher between the ages of $35-44$ years with only one female participant. Most of the study participants are the owner of the pharmacy and have qualified diploma with license to put up a pharmacy. Nearly half of the community pharmacists in the current study were dispensing approximately 10 - 15 prescriptions per day. The details of the demographic characteristics are present in Table 1.

\section{Knowledge}

The transformation of knowledge towards ADRs and PvPI in the study participants before and after the educational intervention was evident. More than $90 \%$ of study participants were aware of the definition of adverse drug reactions at the pre-intervention stage but it was unfortunate that $58.6 \%$ of the participants had a perceptional thought i.e. all the medicines were safe if taken at the right dose, right route and right time. Moreover, more than $60 \%$ of participants were not aware of the existence of the ADR reporting and monitoring system in India or else PvPI during the pre-intervention period. The knowledge regarding the same was improved with the educational intervention can be said to an extent of being statistically significant in two different question items such as the difference between ADE and ADR and the existence of the ADR reporting system or PvPI $(p=0.000)$. During the post-interventional stage, the frequency of correctly answered respondents was increased for two items namely "definition of ADR" and the "Safety of all the medicines while it is taken at the right dose, right route and right time". $(p=0.438$ and 0.576). (Table 2)

\section{Attitude}

During the pre-interventional stage, $31.1 \%$ of the study participants were not willing to report any ADR due to the fear of crime and $43.1 \%$ expressed lack of time to look into issues related to ADR at community pharmacies. $67.3 \%$ of the participants expressed that the ADR reporting and monitoring system was merely a time-consuming process. $86.2 \%$ of the participants reported that ADR reporting would not benefit patients.

Table 1: Socio-demographic characteristics of study participants.

\begin{tabular}{|c|c|c|}
\hline Parameter & Frequency & $\%$ \\
\hline \multicolumn{3}{|l|}{ Age in years } \\
\hline - $\quad 25-34$ & 11 & 18.9 \\
\hline - $35-44$ & 28 & 48.3 \\
\hline - $45-54$ & 13 & 22.4 \\
\hline - $55-64$ & 06 & 10.3 \\
\hline \multicolumn{3}{|l|}{ Gender } \\
\hline - Male & 57 & 98.2 \\
\hline - Female & 01 & 1.7 \\
\hline \multicolumn{3}{|l|}{ Experience in years } \\
\hline - $\quad 0-1$ & 10 & 17.2 \\
\hline - $\quad 1-5$ & 27 & 46.6 \\
\hline - $6-10$ & 16 & 27.6 \\
\hline - $\quad>10$ & 5 & 8.6 \\
\hline \multicolumn{3}{|l|}{ Education } \\
\hline - Diploma in pharmacy & 50 & 86.2 \\
\hline - Bachelor of pharmacy & 7 & 12.1 \\
\hline - Master of pharmacy & 1 & 1.7 \\
\hline \multicolumn{3}{|l|}{ Type of practice } \\
\hline - Sole proprietor & 51 & 86.2 \\
\hline - $\quad$ Manager & 1 & 12.1 \\
\hline - Employee & 6 & 1.7 \\
\hline \multicolumn{3}{|c|}{$\begin{array}{l}\text { Number of prescriptions filled per } \\
\text { day }\end{array}$} \\
\hline . $\quad<10$ & 13 & 22.4 \\
\hline - $10-15$ & 29 & 50.0 \\
\hline . $>15$ & 16 & 27.6 \\
\hline
\end{tabular}


Whereas, $72.4 \%$ of the study participants had stated that the pharmacist's role in ADR reporting and assistance in ADR detection and management are more useful and essential with $65.5 \%$ of which were willing to report $\mathrm{ADR}$ if the ADR reporting forms were distributed to the pharmacies.

Out of the eight items tested for attitude, there was a statistically significant difference among four items in pre and post interventional testing. The post-intervention results shows $91.4 \%$ of study participants thought that pharmacists play an essential role in ADR reporting and is the results were statistically significant from the pre-interventional stage ( $\mathrm{p}$ value 0.014 ). Similarly, the fear of crime towards ADR was reduced and positive thinking was increased significantly in terms of ADR reporting in the post interventional stage ( $p$-value 0.032 and 0.009 ). During post interventional testing $86.2 \%$ of study participants stated that they would report ADRs, if the reporting forms were distributed to their pharmacy ( $p$-value 0.016). Further we observed an increased frequency of correct responses after intervention but were not statistically significant. (Table 3)

\section{Practice}

The frequency of correct responses to practice-related questions in the pre-interventional testing was found very less. $19 \%$ of study participants reported the suspected or identified ADR to the pharmaceutical company which encountered during their practice. Further, a very less number of study participants knew about where to report ADR (34.5\%) and where to obtain the ADR reporting forms (32.7\%) and around $31 \%$ of the study participants reported that the level of clinical knowledge made them difficult to identify and report any ADR. After providing the educational intervention, the statistically significant difference was found only in two items such as how to report ADR and where to obtain ADR reporting forms. (Table 4)

\section{Association of demographics towards KAP}

The core themed question was selected from each domain to test the association between demographics and responses received at the post interventional stage. It was found that most of the demographic characters were not found to have a significant association with various domains of

Table 2: Knowledge of community pharmacists towards adverse drug reaction and its reporting system.

\begin{tabular}{|c|c|c|c|c|}
\hline S.No & Items & $\begin{array}{l}\text { Frequency of correct } \\
\text { answer (pre intervention) } \\
\text { N (\%) }\end{array}$ & $\begin{array}{l}\text { Frequency of correct } \\
\text { answer (post- intervention) } \\
\text { N (\%) }\end{array}$ & $P$ value \\
\hline 1 & Do you know what adverse drug reaction is? & $53(91.4 \%)$ & $56(96.6 \%)$ & 0.438 \\
\hline 2 & $\begin{array}{l}\text { Do you know the difference between adverse event and } \\
\text { adverse effect? }\end{array}$ & $25(43.1 \%)$ & $51(87.9 \%)$ & $0.000^{*}$ \\
\hline 3 & $\begin{array}{l}\text { Do you think all the medicines are safe when you dispense } \\
\text { them even if the patients takes at right dose, right route and } \\
\text { at right time? }\end{array}$ & $24(41.4 \%)$ & $28(48.3 \%)$ & 0.576 \\
\hline 4 & $\begin{array}{l}\text { Are you aware that existence of adverse drug reactions } \\
\text { (ADRs) reporting and monitoring system (National } \\
\text { Pharmacovigilance program) in India? }\end{array}$ & $21(36.2 \%)$ & $44(75.8 \%)$ & $0.000^{*}$ \\
\hline
\end{tabular}

${ }^{*} p$ value $<0.05$ considered significant

Table 3: Attitude of community pharmacists towards adverse drug reaction and its reporting system.

\begin{tabular}{|c|c|c|c|c|}
\hline S.No & Questions & $\begin{array}{l}\text { Frequency of correct answer } \\
\text { (pre intervention) } \\
\mathrm{N}(\%)\end{array}$ & $\begin{array}{l}\text { Frequency of correct answer } \\
\text { (post intervention) } \\
\qquad \mathrm{N}(\%)\end{array}$ & $P$ value \\
\hline 1 & Do you think adverse drug reaction reporting process is time consuming? & $39(67.3 \%)$ & $48(82.8 \%)$ & 0.085 \\
\hline 2 & $\begin{array}{l}\text { Do you think community pharmacists have an essential role to play in } \\
\qquad \text { ADR reporting }\end{array}$ & $42(72.4 \%)$ & $53(91.4 \%)$ & $0.014^{*}$ \\
\hline 3 & $\begin{array}{l}\text { Do you think ADR reporting and monitoring system in your practice } \\
\text { settings, is useful for your practice? }\end{array}$ & $50(86.2 \%)$ & $48(82.8 \%)$ & 0.798 \\
\hline 4 & $\begin{array}{l}\text { Do you think that ADR reporting and monitoring system would benefit } \\
\text { the patient? }\end{array}$ & $50(86.2 \%)$ & $57(98.3 \%)$ & $0.032^{*}$ \\
\hline 5 & $\begin{array}{c}\text { Community pharmacists are usually unwilling to report adverse drug } \\
\text { reactions because of fear of crime }\end{array}$ & $18(31.1 \%)$ & $33(56.9 \%)$ & $0.009^{*}$ \\
\hline 6 & $\begin{array}{l}\text { Do you think that there is lack of time to actively look or an ADR while } \\
\text { at work? }\end{array}$ & $25(43.1 \%)$ & $21(36.2 \%)$ & 0.569 \\
\hline 7 & $\begin{array}{l}\text { Is pharmacist's assistance in detection, reporting and management of } \\
\text { adverse drug reaction useful? }\end{array}$ & $52(89.7 \%)$ & $56(96.3 \%)$ & 0.272 \\
\hline 8 & $\begin{array}{l}\text { Will you able to report an ADR if the reporting forms will be distributed } \\
\text { into the pharmacy? }\end{array}$ & $38(65.5 \%)$ & $50(86.2 \%)$ & $0.016^{*}$ \\
\hline
\end{tabular}

${ }^{*} p$ value $<0.05$ considered significant 
the questionnaire. The age group was one of the factors found to have an impact on knowledge and practice domains ( $p$-value 0.004 and 0.008 ). The educational level was found to have an impact on the practice domain ( $p$-value 0.035). (Table 5)

\section{DISCUSSION}

The ADR reporting in India is getting momentum at the present time. However, it is negligible and almost nonexistent in community pharmacy settings. The continuous professional education is required to encourage the community pharmacists to report the ADRs encountered during their practice. Thus the current study took an opportunity to educate the community pharmacists and to evaluate its impact.

The results of the current study revealed the lack of awareness of the existence of the pharmacovigilance program and ADR reporting process among the majority of participants of the study. Such unawareness about pharmacovigilance among pharmacists was reported from many other parts of India and even in various countries. ${ }^{8,16-18}$ A deficiency in knowledge and perceptions about pharmacovigilance and ADRs reporting is accountable for under-reporting of ADRs in both developed and developing countries. ${ }^{18,19}$ The awareness was increased among the study participants after the educational intervention and similar results were reported by the studies conducted in neighboring states like Tamil Nadu and Kerala. ${ }^{6,20}$ The current study observed around half of the study participants still believe the medicines are safe if the patients takes those at the right dose, right route and at the right time, even during the post interventional stage. This implies the need for hands-on training, continuous evaluation and education and clinical education to all the community pharmacists. ${ }^{21-23}$

Nearly three fourth of community pharmacists felt that reporting ADRs should be mandated. When it is compared with the research published with similarly objectives revealed that studies like Suyagh M. et al. and Prakasam A et al. found a majority of community pharmacists believed that reporting of ADRs should be made necessary ${ }^{8,17}$ which puts up a common understanding with the current research.

In consistence with our findings, Salim et al. reported that more than half of the community pharmacists confirmed that ADR reporting would be beneficial to the patients. ${ }^{20}$

The research evidences shows that ignorance (not feeling the need to report well-recognized reaction), diffidence (concern that the ADR report may be wrong) and indifference (lack of time to fill in a report and a single unreported case may not affect ADR database) were the significant predictors of ADR reporting among physicians..$^{24}$ Meanwhile, the current study demonstrated that the ignorance, fear of crime, lack of time and lack of assistance were the factors causing the under-reporting of ADRs among community pharmacists as well. The educational intervention in the current study had improved the attitude of the study participants. These results were coinciding with the research results conducted by Ganesan $\mathrm{S}$ et al. among health care professionals. ${ }^{25}$

In the current study, very few people have reported suspected adverse drug reactions to the ADR monitoring centers. These results are in contrast with the study published by Joubert et al. and the practice is sustained even after educational intervention.

During the pre-interventional stage, it was very unfortunate that the practice of ADR reporting to the ADR monitoring centers was poor among the study participants and even few participants were reporting the ADR to pharmaceutical companies. These results are in contrast with the study published by Joubert et al. and the practice is sustained even after the educational intervention. ${ }^{26}$

A study conducted in Nigeria among community pharmacists also stated that ADR reporting incidences are very rare even though they enough knowledge. ${ }^{27}$ In the current study, the practice of ADR reporting was not improved even after the educational intervention which is in contrast with the study published by Abimbola et al..$^{28}$ It was also noted that the theoretical educational intervention seems to be unsuccessful to change the practice of community pharmacists. This may warrant the need for practical hands-on training and clinical education to improve the practice of ADR reporting among community pharmacists. ${ }^{29,30}$

A study reported the relation between the demographic characters and their association with ADR reporting, where the participants aged more than 36 years were reported more ADRs than younger age groups. ${ }^{31}$ In the current study, we found that the age group was found to have strong association with ADR reporting. On the other hand educational level of community pharmacists is also found to have a major impact on ADR reporting. Similarly, the study conducted among physicians in Saudi Arabia reported that job category, highest level of education and age were associated to ADR reporting. ${ }^{32}$

\section{Limitations of the study}

The main limitation of the current study was a relatively small number of samples. Besides, it was conducted in the rural part of south India and confined to one particular district of Andhra Pradesh. The difference existing between the urban and rural community pharmacists may diminish the possibility of generalizability of the results. However, this survey can serve as a preliminary study and is valued in providing insights into perceptions of Indian pharmacists on issues regarding adverse drug reactions.

Table 4: Practice of community pharmacists towards adverse drug reaction and its reporting system.

\begin{tabular}{|c|c|c|c|c|}
\hline S.No & Characteristics & $\begin{array}{c}\text { Frequency of correct } \\
\text { answer (pre intervention) } \\
\mathrm{N}(\%)\end{array}$ & $\begin{array}{c}\text { Frequency of correct } \\
\text { answer (post intervention) } \\
\mathrm{N}(\%)\end{array}$ & $P$ value \\
\hline 2 & Do you know where to obtain the ADR forms & $19(32.7 \%)$ & $45(77.6 \%)$ & $0.000^{*}$ \\
\hline 3 & Have you ever observed a suspected adverse drug reaction? & $23(39.7 \%)$ & $23(39.7 \%)$ & 1.000 \\
\hline 5 & $\begin{array}{l}\text { Do you think that your level of clinical knowledge makes it difficult to } \\
\text { decide whether or not an ADR has occurred? }\end{array}$ & $18(31 \%)$ & $19(32.8 \%)$ & 1.000 \\
\hline 6 & Did you report any ADR to Company? & $47(81.03 \%)$ & $53(91.4 \%)$ & 0.177 \\
\hline
\end{tabular}

${ }^{*} p$ value $<0.05$ considered significant 
Table 5: Association of demographic characteristics to KAP on PvPI and ADR reporting (Selected items on questionnaire).

\begin{tabular}{|c|c|c|c|c|c|c|}
\hline \multirow[t]{2}{*}{ Demographic characters } & \multicolumn{2}{|c|}{$\begin{array}{l}\text { Knowledge } \\
\text { Are you aware that existence of adverse } \\
\text { drug reactions (ADRs) reporting } \\
\text { and monitoring system (National } \\
\text { Pharmacovigilance program) in India? }\end{array}$} & \multicolumn{2}{|c|}{$\begin{array}{l}\text { Attitude } \\
\text { Will you able to report an ADR if the } \\
\text { reporting forms will be distributed } \\
\text { into the pharmacy? }\end{array}$} & \multicolumn{2}{|c|}{$\begin{array}{l}\text { Practice } \\
\text { Do you think that your level } \\
\text { of clinical knowledge makes it } \\
\text { difficult to decide whether or } \\
\text { not an ADR has occurred? }\end{array}$} \\
\hline & Frequency & $P$ value & Frequency & $P$ value & Frequency & $P$ value \\
\hline \multicolumn{7}{|l|}{ Age in years } \\
\hline $25-34$ & 9 & & 6 & & 7 & \\
\hline $35-44$ & 24 & $0.004^{*}$ & 25 & 0.703 & 11 & $0.008^{*}$ \\
\hline $45-54$ & 10 & & 10 & & 1 & \\
\hline $55-64$ & 1 & & 5 & & 0 & \\
\hline \multicolumn{7}{|l|}{ Gender } \\
\hline Male & 44 & 1.000 & 49 & 1.000 & 19 & 1.000 \\
\hline Female & 0 & & 1 & & 0 & \\
\hline \multicolumn{7}{|l|}{ Experience in years } \\
\hline $0-1$ & 8 & & 9 & & 6 & \\
\hline $1-5$ & 23 & 0.149 & 25 & 0.407 & 11 & 0.149 \\
\hline $6-10$ & 11 & & 12 & & 2 & \\
\hline$>10$ & 2 & & 4 & & 0 & \\
\hline \multicolumn{7}{|l|}{ Education } \\
\hline Diploma in Pharmacy & 36 & & 42 & & 14 & \\
\hline Bachelor of Pharmacy & 7 & 0.228 & 7 & 0.476 & 5 & $0.035^{*}$ \\
\hline Master of Pharmacy & 1 & & 1 & & 0 & \\
\hline \multicolumn{7}{|l|}{ Type of practice } \\
\hline Sole proprietor & 39 & & 44 & & 16 & \\
\hline Manager & 1 & 0.739 & 1 & 0.904 & 0 & 0.511 \\
\hline Employee & 4 & & 5 & & 3 & \\
\hline \multicolumn{7}{|l|}{ No. of prescriptions filled per } \\
\hline$<10$ & 20 & 0.262 & 25 & 0.692 & 11 & 0.111 \\
\hline $10-15$ & 12 & & 13 & & 2 & \\
\hline$>15$ & & & & & & \\
\hline
\end{tabular}

${ }^{*} p$ value $<0.05$ considered significant

\section{CONCLUSION}

The results of the current study indicated that the educational programs focusing on ADRs will improve the KAP among community pharmacists. Therefore, it is necessary to offer continuous educational programs and hands-on training to all the community pharmacists in Indian settings until we reach the point that voluntary reporting of adverse drug reactions becomes conventional and habitual.

\section{ACKNOWLEDGEMENT}

The authors are thankful to Anantapur district chemists and druggists association (ADCDA), Rural development trust hospital (RDT) Bathalapalli and Association of community pharmacists of India (ACPI) for their moral support in conducting the CPE. The authors are also thankful to Dr. Y. Padmanabha Reddy, Principal, Raghavendra Institute of Pharmaceutical Education and Research (RIPER) for his extensive support in the completion of this research work.

\section{CONFLICT OF INTEREST}

The authors declare no conflicting interests.

\section{ABBREVIATIONS}

ADR: Adverse drug reactions; ADE: Adverse drug events; KAP: Knowledge, Attitude and Practice; SRSs: Spontaneous reporting systems; IPC: Indian pharmacopoeia commission; MoHFW: Ministry of health and family welfare; NCC: National Co-ordination centre; PvPI: Pharmacovigilance program of India; SMS: Short message service; SPSS: Statistical package for social sciences.

\section{REFERENCES}

1. Elkalmi RM, Hassali MA, Ibrahim MIM, Liau SY, Awaisu A. A qualitative study exploring barriers and facilitators for reporting of adverse drug reactions (ADRs) among community pharmacists in Malaysia. J Pharm Health Serv Res. $2011 ; 2(2): 71-8$.

2. Piparva KGP, Anil PS. A Cross Sectional Pilot Study of Knowledge, Attitude and Practice of Pharmacovigilance among Pharmacists at Rajkot District. J Basic Clin Pharm. 2017;8(S2):S20-3.

3. Bhagavathula AS, Elnour AA, Jamshed SQ, Shehab A. Health Professionals' Knowledge, Attitudes and Practices about Pharmacovigilance in India: A Systematic Review and Meta-Analysis. Plos One. 2016;11(3):e0152221.

4. Palaian S, Ibrahim MI, Mishra P. Health professionals' knowledge, attitude and practices towards pharmacovigilance in Nepal. Pharm Pract Internet. 2011;9(4):228-35.

5. Khalili H, Mohebbi N, Hendoiee N, Keshtkar AA, Dashti-Khavidaki S. Improve- 
ment of knowledge, attitude and perception of healthcare workers about ADR, a pre- and post-clinical pharmacists' interventional study. BMJ Open. 2012;2(1):e000367.

6. Deepalakshmi M, Kumar P, Arun KP, Ponnusankar S. Impact of Continuing Pharmacy Education on the Knowledge. Attitude and Practice of Community Pharmacists about ADR Monitoring and Reporting. Indian J Pharm Sci. 2019;81(4):633-9.

7. Khan TM. Community pharmacists' knowledge and perceptions about adverse drug reactions and barriers towards their reporting in Eastern region, Alahsa, Saudi Arabia. Ther Adv Drug Saf. 2013;4(2):45-51.

8. Prakasam A, Nidamanuri A, Kumar S. Knowledge, perception and practice of pharmacovigilance among community pharmacists in South India. Pharm Pract. 2012;10(4):222-6.

9. Elkalmi RM, Hassali MA, Ibrahim MIM, Widodo RT, Efan QMA, Hadi MA. Pharmacy Students' Knowledge and Perceptions about Pharmacovigilance in Malaysian Public Universities. Am J Pharm Educ. 2011;75(5):96.

10. Kalaiselvan $V$, Kumar $P$, Mishra $P$, Singh G. System of adverse drug reactions reporting: What, where, how and whom to report?. Indian J Crit Care Med. 2015;19(9):564.

11. Kalaiselvan V, Thota P, Singh GN. Pharmacovigilance Programme of India: Recent developments and future perspectives. Indian J Pharmacol. 2016;48(6):624-8.

12. AlDweik $R$, Stacey $D$, Kohen D, Yaya $S$. Factor's affecting patient reporting of adverse drug reactions: A systematic review. Br J Clin Pharmacol. 2017;83(4):87583.

13. Rajesh R, Vidyasagar S, Varma DM. An Educational Intervention to assess Knowledge Attitude Practice of pharmacovigilance among Health care professionals in an Indian tertiary care teaching hospital. Int J PharmTech Res. 2011;3(2):678-92.

14. Bo J, Oj O, Oo I, So O. Unmodified electroconvulsive therapy: Changes in knowledge and attitudes of Nigerian medical students. African Health Sciences. 2009;9(4):280-3

15. Ariyanto AA, Muluk $H$, Newcombe P, Piercy FP, Poerwandari EK, Suradijono SHR. Diversity in Unity: Perspectives from Psychology and Behavioral Sciences. $1^{\text {st }}$ ed. Routledge. 2017;662. [cited 2019 Nov 29]. Available from: https:// www.taylorfrancis.com/books/9781351846493

16. Qassim S, Metwaly Z, Shamsain M, Hariri YA. Reporting Adverse Drug Reactions: Evaluation of Knowledge, Attitude and Practice among Community Pharmacists in UAE. IOSR J Pharm. 2014;22(30):31-40.

17. Suyagh M, Farah D, Abu FR. Pharmacist's knowledge, practice and attitudes toward pharmacovigilance and adverse drug reactions reporting process. Saudi Pharm J. 2015;23(2):147-53.

18. Piparva KG, Singh AP. A Cross Sectional Pilot Study of Knowledge, Attitude and Practice of Pharmacovigilance among Pharmacists at Rajkot District. J Basic Clin Pharm. 2017:8(S020):S0020-3.

19. Sajida S, Jaffar SM, Balaji K, Narayana G. A Possible case of complete loss of Vision after Intra Ocular Administration of Bevacizumab: Case Report. Indian J
Pharm Pract. 2013;6(1):82-3.

20. Nimisha HMS, Muhammed LTB. The Current Perspective of Community Pharmacists towards Pharmacovigilance. J Pharmacovigil. 2015;3(180):2. Available from: http://www.esciencecentral.org/journals/the-current-perspectiveof-community-pharmacists-towards-pharmacovigilance-2329-6887-1000180. php?aid $=61499$

21. Jha N, Rathore DS, Shankar PR, Bhandary S, Pandit RB, Gyawali S, et al. Effect of an educational intervention on knowledge and attitude regarding pharmacovigilance and consumer pharmacovigilance among community pharmacists in Lalitpur district, Nepal. BMC Res Notes. 2017;10(1):4.

22. Vigneshwaran E, Sadiq MM, Prathima V. Assessment of completeness and legibility of prescriptions received at community pharmacies. J Health Res Rev. 2016;3(2):72-6.

23. Srujana MP, Vigneshwaran E, Kumar GS, Jyoshna K, Jaffar SMM. Assessment of quality of life in children with epilepsy in rural settings of South India: A cross sectional study. CHRISMED J Health Res. 2017;4(2):110-6.

24. Oshikoya KA, Awobusuyi JO. Perceptions of doctors to adverse drug reaction reporting in a teaching hospital in Lagos, Nigeria. BMC Clin Pharmacol. 2009;9(1):14.

25. Ganesan S, Sandhiya S, Reddy KC, Subrahmanyam DK, Adithan C. The Impact of the Educational Intervention on Knowledge, Attitude and Practice of Pharmacovigilance toward Adverse Drug Reactions Reporting among Health-care Professionals in a Tertiary Care Hospital in South India. J Nat Sci Biol Med. 2017;8(2):203-9.

26. Joubert MC, Naidoo P. Knowledge, perceptions and practices of pharmacovigilance amongst community and hospital pharmacists in a selected district of North West Province, South Africa. Health SA Gesondheid. 2016;21:238-44

27. Usifoh SF, Aika IN, Odili VU, Nwokoro JO. Community Pharmacists Knowledge, Behaviours and Practice of Adverse Drug Reactions Reporting in Lagos State Nigeria. Indian J Pharm Pract. 2018;11(1):07-13.

28. Opadeyi $A O$, Fourrier-Réglat $A$, Isah $A O$. Educational intervention to improve the knowledge, attitude and practice of healthcare professionals regarding pharmacovigilance in South-South Nigeria. Ther Adv Drug Saf. 2019;10:2042098618816279.

29. Lemay J, Alsaleh FM, Al-Buresli L, Al-Mutairi M, Abahussain EA, Bayoud T. Reporting of Adverse Drug Reactions in Primary Care Settings in Kuwait: A Comparative Study of Physicians and Pharmacists. Med Princ Pract. 2018;27(1):30-8.

30. Goel D. Impact of educational intervention on knowledge, attitude and practice of pharmacovigilance among nurses. Arch Med Health Sci. 2018;6(1):32.

31. Katusiime B, Semakula D, Lubinga SJ. Adverse drug reaction reporting among health care workers at Mulago National Referral and Teaching hospital in Uganda. Afr Health Sci. 2015;15(4):1308-17.

32. Bakhsh T, Al-Ghamdi M, Bawazir S, Al-Raddadi R, Qureshi N. Physicians Sociodemographics and Knowledge, Awareness, Attitude and Practice towards Reporting Adverse Drug Reactions: An Association Study in Jeddah City, Saudi Arabia. Br J Pharm Res. 2016;12(3):1-15.

Article History: Submission Date :07-01-2020 ; Revised Date : 27-01-2020 ; Acceptance Date : 20-02-2020

Cite this article: Vigneshwaran E, Harichandana V, Sadiq MMJ, Alavudeen SS, Khan NA, Ahmed T.Knowledge, Attitude and Practice of Community Pharmacists towards Adverse Drug Reactions Reporting. J Young Pharm. 2020;12(1):75-80. 